\title{
Heifer International Alternative Break: Sustainable Dietary Impacts
}

\section{Authors: Carmen Byker, Susan Clark, J. Rex Enoch, Todd Montgomery, \& Elena Serrano}

This is an Accepted Manuscript of an article published in Journal of Hunger and Environmental Nutrition on September 4, 2012, available online:

http://www.tandfonline.com/10.1080/19320248.2012.703470.

Byker, C., Clark, S., Enoch, R.J., Montgomery, T., \& Serrano, E. (2012). Heifer International Alternative Break: Sustainable Dietary Impacts. Journal of Hunger and Environmental Nutrition. $7(2), 122-136$. 


\title{
Heifer International Alternative Break: Sustainable Dietary Impacts
}

\author{
Carmen Byker ${ }^{1}$, Susan Clark 2 , J. Rex Enoch ${ }^{3}$, Todd Montgomery ${ }^{4}$, \& Elena Serrano ${ }^{2}$ \\ ${ }^{1}$ Department of Health and Human Development, Montana State University, \\ Bozeman, Montana, USA \\ ${ }^{2}$ Department of Human Nutrition, Foods and Exercise, Virginia Tech, \\ Blacksburg, Virginia, USA \\ ${ }^{3}$ Department of Sociology, University of Arkansas at Little Rock, Little Rock, \\ Arkansas, USA \\ ${ }^{4}$ Heifer International, Little Rock, Arkansas, USA
}

This study examines Heifer International's alternative break and its impact on dietary and sustainable food system change for participants. The program teaches college participants about ending poverty and hunger while caring for the earth through incorporating sustainable practices into daily life. Although increases in local/organic foods were observed, there were no significant changes in dietary quality. Significant increases in local/organic food consumption for individuals who consumed less than 50\% of their calories from sustainable foods at baseline were observed, based upon paired t-tests $(P<.05)$. Dietary changes varied in significance based upon previous sustainable food consumption exposure and habits.

KEYWORDS food system, Heifer International, nutrition, sustainability, student

There is a nascent trend for American college and university campuses to go green. The Sustainable Endowments Institute, a nonprofit focused on advancing sustainability on campuses, tracks progress and grades green universities across the nation. ${ }^{1}$ One of the avenues for campus sustainability 
promotion is through sustainable food system advocacy. Campus dining services feature sustainable food programs. ${ }^{2}$ Emerging academic programs concentrate on sustainable food system practices, including agriculture, nutrition, economics, and population health. ${ }^{3}$ Students are beginning to participate in community-based efforts that focus on sustainable food systems, also called civic agriculture. ${ }^{4}$ A sustainable food system education is appropriate and necessary for contemporary higher education because the tenets of sustainability-individual and environmental health, economic profitability, and social justice-are important issues for all students to consider and are themes that appear across curriculums.,

Little research has been completed about the perceptions or effects of sustainable food system education on the collegiate diet and larger food system implications. ${ }^{7}$ Studies completed about the college student's diet focus on a change in general consumption practices as a result of new independence in choice about what to eat. ${ }^{8-11}$ This article focuses on one example of sustainable food system education at the university level and reports the dietary and food system implications of that program.

\section{BACKGROUND}

In partnership with Heifer International (HI), Virginia Tech (VT) coordinates two alternative break (AB) trips to the nonprofit's Learning Center at $\mathrm{HI}$ Ranch (HR) in Little Rock, Arkansas, and HI Honduras (HH) project sites. This study focused on 3 trips in 2010 (HR1) and 2011 (HR2 and HH1). The mission of $\mathrm{HI}$ is to "work with communities to end hunger and poverty and care for the earth." ${ }^{12(\mathrm{p} 123)}$ With gifts of livestock, seeds, education, and training, HI gives a family tools to succeed, who then "pass the gift" to other families in the community. ${ }^{12}$ Utilizing the experiential learning model, students visited the Learning Center at HR and/or HH project sites to "experience challenges of global hunger and poverty-and return with re-energized determination to be a part of the solution." ${ }^{13}$

With livestock, various produce gardens, and country-specific cooking and energy-producing equipment, HR aims to provide a model simulation of the work completed through HI in countries around the world. ${ }^{13}$ The HH study tour places students into the environment where HI projects occur. ${ }^{13}$ Both educate students about HI's work, mission, and how to incorporate food system sustainability practices into daily life, helping to solve global poverty and hunger. Specifically, through the alternative spring break (ASB) experiences college students learn that they are part of a socio-ecological matrix in which their personal actions impact living systems on a global, national, regional, and local level. ${ }^{14}$ This study examined the impacts that the HI AB programs had on students' perceptions and behaviors regarding sustainable food systems before and after the content and experience of the course. 


\section{METHODS}

\section{Research Design}

To measure the effectiveness of $\mathrm{HI} \mathrm{AB}$ programs on student perceptions of and practices with regard to sustainable food systems, participants provided informed consent and completed a series of surveys, dietary recalls, and journal prompts. Using a participatory approach ${ }^{15}$ and the socio-ecological model as a guide, ${ }^{16}$ researchers and HI worked in conjunction to modify $\mathrm{AB}$ curriculum to be appropriate for college-age students. In addition, measurement instruments were developed. The design was quasi-experimental, using a one-group pretest, posttest, and follow-up, with no control group. This research primarily seeks to detect attitude changes and impacts, motivation, and behavior toward sustainable food systems and HI's mission. The secondary aim was to detect improvement areas for the $\mathrm{HI} A B$ program to accommodate college-age participants and better address sustainable food systems. VT's Institutional Review Board approved this study with informed consent provided by all participants. This material is based upon work supported by the United States Department of Agriculture Higher Education Challenge (HEC) grant under Award No. 2009-38411-19770.

\section{Recruitment}

The subject pool included all VT students (see Table 1). Being unable to attend the $\mathrm{AB}$ was the only exclusion criteria. For HR1 and HR2, student recruitment initially occurred though advertisements to the entire student body (eg, flyers, word of mouth, student registration page), with courses limited to 25 students. For HH1 (enrollment limited to 10), students who previously attended HR1 were first recruited to attend, with remaining spaces open to students studying food systems. Students were introduced to the study through class. Participation was voluntary.

\section{Settings-Overview of Heifer Alternative Breaks}

HR1 and HR2 included experiential learning activities that modeled sustainable agriculture occurring around the world. Beyond activities, students attended classroom sessions to learn about global hunger and HI's mission and proposed solutions. During the classroom sessions, student groups identified issues in their local community and worked within HI's model to propose solutions and plan implementation steps.

HH1 included classroom learning, service-learning projects, and site tours at current HI Honduras project sites. Classroom learning prepared students for the status of hunger, political climate, and culture of Honduras. Service learning involved building structures alongside peasant farmers, or 'campesino', who were beginning a sustainable community. Students 
TABLE 1 Demographic Percentages of 3 Heifer International Alternative Spring Break Programs Compared to VT Population in 2010

\begin{tabular}{|c|c|c|c|c|c|c|}
\hline Demographics & Ranch 2010 & Ranch 2011 & Honduras 2011 & Pre-Post & Follow-up & VT \\
\hline Enrollment $(n)$ & 20 & 12 & 8 & 39 & 22 & 28687 \\
\hline \multicolumn{7}{|l|}{ Gender (\%) } \\
\hline Male & 21 & 17 & 13 & 18 & 18 & 58 \\
\hline Female & 79 & 83 & 87 & 82 & 82 & 42 \\
\hline \multicolumn{7}{|l|}{ Race (\%) } \\
\hline White & 90 & 83 & 87 & 87 & 91 & 77 \\
\hline Asian & 5 & 8 & 13 & 8 & 0 & 7 \\
\hline Other & 5 & 8 & 0 & 5 & 9 & NA \\
\hline \multicolumn{7}{|l|}{ College level (\%) } \\
\hline Freshman & 40 & 42 & 0 & 32 & 18 & 18 \\
\hline Sophomore & 15 & 8 & 25 & 15 & 23 & NA \\
\hline Junior & 15 & 33 & 13 & 21 & 18 & NA \\
\hline Senior & 20 & 17 & 50 & 26 & 36 & NA \\
\hline Fifth-year senior & 0 & 0 & 13 & 3 & 0 & NA \\
\hline Master's & 0 & 0 & 0 & 0 & 0 & NA \\
\hline $\mathrm{PhD}$ & 10 & 0 & 0 & 3 & 5 & NA \\
\hline Age $(M \pm S D)$ & $21 \pm 4$ & $21 \pm 3$ & $21 \pm 1$ & $21 \pm 3$ & $20 \pm 5$ & NA \\
\hline \multicolumn{7}{|l|}{ CAFS minor (\%) } \\
\hline Enrolled & 21 & 67 & 75 & 54 & 50 & 0.11 \\
\hline Not enrolled & 79 & 33 & 25 & 46 & 50 & 99.9 \\
\hline
\end{tabular}

independently brainstormed issues in their local community that had potential to be solved using HI's model.

\section{MEASURES}

\section{Dietary Recalls}

Participants completed modified 3-day dietary recalls pretest and posttest to document food and beverage consumption over a 3-day consecutive time period, using a portion guideline. ${ }^{17-19}$ Follow-up measures included 24-hour recalls. Both recalls were modified to include a section for documenting food procurement (ie, dining hall, grocery store) and growing method (ie, organic or local). The purpose of the dietary recalls was to measure changes in local or organic food consumption, signifying dietary engagement in a sustainable food system.

\section{HI Alternative Spring Break Questionnaire}

A questionnaire was developed, because no other reliable or validated instrument assesses questions about the impacts of $\mathrm{AB}$ programs on sustainable food system attitudes, motivation, and behavior at pretest, posttest, and follow-up. Demographic information was collected. The main components of the questionnaire addressed sustainable food system participation. 
The questions were tested for content validity with health educators and revised accordingly. The questionnaire took approximately 10 minutes to complete.

\title{
Journal Entries
}

In order to assess individual attitudes, motivations, and behavior changes with regard to sustainable food systems, students responded to journal prompts during HR1, HR2, and HH1. Students transcribed journal entries into e-portfolios for personal record and research use. Questions focused on the individual's knowledge of $\mathrm{HI}$, expectations about and experiences at the $\mathrm{AB}$ program, cultural values, attitudes toward sustainable agriculture and community development, and individual behavioral practices regarding what was learned.

\section{Focus Group Discussions}

Audio-recorded focus group discussions tracked progress and barriers on planned projects, as well as adherence to sustainable food system practices. Questions were semistructured and focused on participation motivation; personal food behaviors; long-term behavior maintenance and barriers; perceptions about effects of personal behaviors on the environment; program improvement; and planned community project progress. Trained moderators and note takers conducted 2 one-hour focus groups. Participants were randomly divided into 2 groups to obtain an optimal number. ${ }^{20}$

\begin{abstract}
ANALYSIS
All quantitative dietary and survey data were entered into Microsoft Excel and then converted into SPSS statistical software, version 11.0. ${ }^{21}$ Data were analyzed as 3 independent groups (HR1, HR2, HH1) and as one group. Descriptive statistics and frequencies were computed for participant demographics. The Wilcoxon signed-rank test calculated changes in questionnaire data regarding attitudes toward sustainable food systems at pretest, posttest, and follow-up. The Kruskal-Wallis test or Pearson's chi-square test of independence $\left(\chi^{2}\right)$ detected differences between groups regarding questionnaire data.

Information from dietary records was analyzed using the Nutritionist Pro Diet Analysis Module. ${ }^{22}$ Paired $t$-tests were used to test the effect of the intervention on dietary intake for total kilocalories of total, local, organic, the sum of local and organic foods, and changes in dietary quality. To assess changes in dietary quality due to increased local and organic food consumption, individuals who increased local and organic food intake were separated from
\end{abstract}


individuals who decreased local and organic food intake. Paired $t$-tests were used to analyze the effect that increases or decreases in local and organic food consumption had on macro- and micronutrient consumption and fruit and vegetable intake.

Journal entries and focus groups were transcribed and coded for major and minor themes using an inductive process. ${ }^{23}$ Codes were categorized into themes. A second researcher verified transcripts, codes, and themes. Participant responses were retrieved from transcripts to support themes.

Two separate analyses were conducted for questionnaires and dietary recalls_-one analysis for participants who completed pretest to posttest data and an additional analysis for participants who completed pretest to posttest to follow-up data. Due to low numbers for follow-up data, pretest to posttest information is reported in the Results, with a portion of the Discussion devoted to follow-up data.

\section{RESULTS}

\section{Participants}

Overall, 43 participants were eligible to participate. Thirty-nine participants provided informed consent and completed all presurvey protocol (HR1, $n=19$; HR2, $n=12$; HH1, $n=8)$. Four participants out of 39 (10\%) attended both HR1 and HH1, meaning that data were collected twice 4 four participants. See Table 1 for demographic information.

\section{HI Alternative Spring Break Questionnaire}

HR1 $(n=19)$, HR2 $(n=12)$, and HH1 $(n=8)$ differed in pretest to posttest changes regarding rank order questions tested: (1) the importance of climate change, composting, biodiversity, natural resource use, overconsumption, pollution, recycling, and waste; (2) interest in foods that are organic, fair trade, local, cheap, humanely treat animals, protect the earth, or healthier. Specifically, HR1 significantly $(P<.05)$ increased the importance they placed on the following issues: composting; natural resource use; recycling; and food that protects the earth. No significant differences were detected for HR2. For HH1, significant $(P<.05)$ increases were noted for recycling and waste. There were no significant differences for any groups when asked how many miles food should be grown within to be labeled local or the perceived percentage of sustainably produced food consumed. When combined, there was a significant $(P<.05)$ increase in the importance placed on fair trade food from pretest to posttest. There were no significant differences noted between ranks of each group regarding the sustainable food systems survey using the Kruskal-Wallis test. 


\section{Dietary Quality}

Thirty-eight participants completed 3-day dietary recalls from pretest to posttest (see Table 2). There were no significant differences found in percentage of local or organic kilocalories consumed by participants or total kilocalories reported when analyzing the $3 \mathrm{AB}$ groups independently from pretest to posttest, based upon a paired $t$-test. Significant $(P<.05)$ differences were found when all 3 groups were combined for local and organic foods. For participants who consumed less than 50\% of their calories from local or organic foods at pretest $(n=19)$, significant increases $(P<.05)$ occurred in the percentage of local $\left(M_{\text {pre }}=\right.$ $\left.0.01, S D_{\text {pre }}=0.02 ; M_{\text {post }}=0.06, S D_{\text {post }}=0.09\right)$ and organic $\left(M_{\text {pre }}=0.04\right.$, $\left.S D_{\text {pre }}=.05 ; M_{\text {post }}=0.15, S D_{\text {post }}=0.16\right)$ foods, based on a paired $t$-test. For participants $(n=19)$ who consumed greater than $50 \%$ of their calories from local $\left(M_{\text {pre }}=0.20, S D_{\text {pre }}=0.18 ; M_{\text {post }}=0.19, S D_{\text {post }}=0.15\right)$ or organic $\left(M_{\text {pre }}=0.26, S D_{\text {pre }}=0.17 ; M_{\text {post }}=0.28, S D_{\text {post }}=0.19\right)$ foods at pretest, no significant increases or decreases were found at posttest.

When examining whether an increase in the percentage of local and organic food consumption impacts dietary quality, there were no significant differences in micro- or macronutrients or fruit and vegetable consumption. Based upon Pearson's chi-square test of independence $\left(\chi^{2}\right)$, no significant differences were found based on whether a student consumed greater than $50 \%$ of food from dining halls on campus or not. Using an independent $t$ test, there were no significant differences found in dietary intake from pretest to posttest based on those who attended HR1, HR2, and HH1 $(n=4)$ and those who only attended one $\mathrm{AB}(n=34)$.

\section{Journal Entries}

Participants enrolled in the $\mathrm{AB}$ programs responded to journal questions throughout the course and trip to promote personal reflection and collect individual-level qualitative data regarding the experience $(n=37)$. Emergent themes are reported.

\section{Information Known About HI Previous to Trip Attendance}

The groups had knowledge on very different information about HI before attendance. In general, HR1 knew surface-level information gathered from the website and through family donations to the nonprofit. HH2 participants knew extensively about the organization and $\mathrm{AB}$ experiences through peers, education, and church programs. $\mathrm{HH} 1$ participants were very aware of $\mathrm{HI}$ due to previous $\mathrm{AB}$ experience at the ranch or enrollment food system education. 


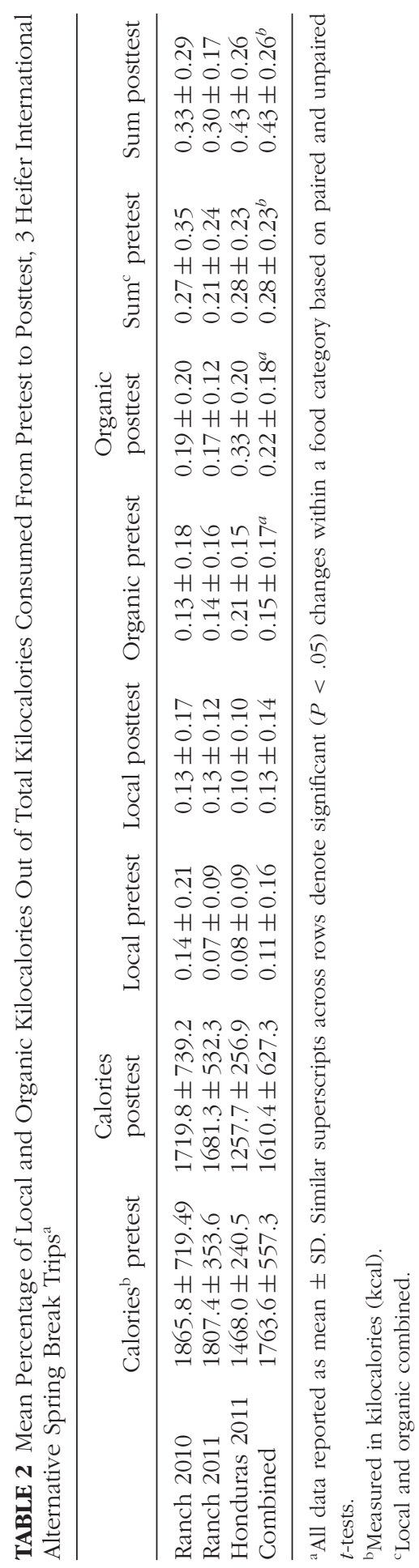




\section{Defining Sustainable Agriculture}

Participants defined sustainable agriculture depending on previous knowledge and experiences, especially in regards to coursework. One participant who was fairly new to the concept reported:

My newfound definition of sustainable agriculture is a farming practice that aims to establish a successful system that benefits the entire community. Instead of focusing on the individual and maximum profit, sustainable agriculture instead focuses on the quality versus the quantity. (HR1)

Across groups, subthemes that emerged regarding sustainable agriculture included community development, environmental consciousness, social justice, and defining it as a grassroots movement.

\section{Levels of Immersion}

In general, participants of HR1 and HR2 wished for a deeper level of immersion in activities. For example, while at HI Ranch, participants spent the night in model houses constructed to look like countries where their nonprofit work exists around the world. HH1 participants experience real life in a less developed country. HR1 and HR2 reported learning about community development given their experience but wished for greater simulation. HH1 participants reported feelings of surprise, guilt about their own "excessive" lifestyles, and a desire to change the situation of world poverty and hunger.

\section{Passing the Gift}

When asked how each participant planned to pass the gift of knowledge about community development learned at the AB, themes emerged about supporting sustainable food systems, sharing HI information, and integrating sustainable agriculture into coursework.

Since Spring Break I have been much more conscious of decisions I make and actions I take. I ride my bike more often instead of driving my car while encouraging my roommates to use alternative forms of transportation. I buy more groceries more frequently from [a local grocery store], looking first for fair trade products, then organic and as close to this area as possible. ... I have been volunteering more and have been spreading messages and opportunities for members of my frat to be conscious of the food decisions that they make. (HR1)

The emergent themes from journal entries revealed that participants entered $\mathrm{AB}$ with various levels of knowledge about $\mathrm{HI}$ and sustainable food systems, 
both of which may influence behavioral changes made. Participants desired a deeper level of immersion, especially at HI Ranch, which may also influence short- and long-term changes made in regards to sustainable food systems. Lastly, students desired to pass the gift through sustainable food system changes.

\section{Focus Groups}

Two focus groups were conducted with all 3 AB programs. Participants included 52\% $(n=10)$ from Ranch 2010, 67\% $(n=8)$ from Ranch 2011, and 88\% $(n=7)$ from Honduras. Overall, 64\% $(n=25)$ from all 3 trips participated. Emergent themes are reported.

\section{Motivation to Participate in AB Program}

Students were motivated to participate in AB programs for 3 reasons: (1) to see HI's model in action; (2) interest in sustainable food systems and education; (3) recruitment through word of mouth.

\section{Effects of AB Program on Behavior}

Students identified the impacts that $\mathrm{AB}$ had on individual behaviors as follows: (1) change in professional goals to include community development through food; (2) involvement in community development related to food; (3) greater consciousness about food choices; and (4) confirmation of previously existing sustainable food practices.

I think that trip really made me personally and others feel a lot more conscious about where you're getting your food from because you see how much labor goes into producing a bushel of coffee. . . . The choices I make as a consumer now, to have an understanding of the purchasing power of my dollar, and how that can affect other people's livelihoods. (HR1 and HH1)

\section{Perceptions of Effects of Behavior on the Environment}

Participants described the following individual behaviors as influencing the physical and social environment around them: (1) composting; (2) gardening; (3) consuming less food and material goods to reduce waste; and (4) influencing peers with personal behaviors.

I just built a compost area at my house. . . I just love seeing that sitting in my kitchen knowing that it's going to go out to my kitchen, and eventually in my garden ... [my roommates] understand the value of it. 
... They see it on your face that you love it so much and they think well it has a to be a good thing so they might do it themselves in the future. (HH1)

\section{Barriers to Behavior Change}

Although students were very interested in sustainable food systems, they also identified barriers to maintaining behavior change: (1) finances; (2) campus dining plan; (3) changing routine; and (4) convenience.

We went out and were weeding gardens, fixing beds, and spreading compost and building things. It was great and then we come back [to university] and, as we said, we all have our routines. I wish I could spend more time in my garden. I am a full time student, I have a family; I don't have the time that we had when we were there. So life gets in the way. (HR1)

\section{Progress and Maintenance of Planned Community Projects}

Students brainstormed community-based projects while at $\mathrm{HI}$ Ranch and were asked to identify projects individually at HH1. Project examples included incorporating sustainable food system content into coursework; increasing the amount of local and organic food in dining halls; installing demonstration sustainable gardens on campus; and starting a resident hall composting program.

\section{Recommendations for AB Programs}

Overall, HI Ranch and HH1 participants felt satisfied with their experience. Recommendations for further integrating the $\mathrm{AB}$ curriculums were given: (1) prepare a pretrip curriculum; (2) more experiential learning; (3) connecting the HI Ranch and HH1 trips into a stepwise experience; and (4) facilitate deeper level learning.

The resultant emergent themes from focus group discussions revealed that peer influence, food system education, and interest in HI and sustainable food systems influenced HI AB enrollment. In general, short- and long-term changes in regards to food system participation occurred and students perceived their own actions as influencing the environment, but overall there were several barriers to maintaining behavior changes.

\section{DISCUSSION}

For pretest to posttest participant data, the intervention was correlated with increases in local and organic food consumption for individuals who 
consumed less than 50\% of their calories from local and organic foods at pretest. Even so, there was no change in dietary quality. This is contrary to findings in the 100-Mile Diet Study (which studied the impacts of a onemonth local foods diet on participants dietary outcomes), where participants increased local food intake to $81 \%$ of kilocalories. ${ }^{24}$ In the study, fruit and vegetable intake increased by 1.4 servings and other significant macro- and micronutrient outcomes were found. Perhaps the percentage (30\%-40\%) of local and organic foods found in participants' diets is not a large enough effect to change dietary outcomes. Many organic foods can be purchased at the grocery store and are not necessarily healthy foods (ie, organic ice cream, organic cheese puffs). Possibly focusing on a local foods diet only increases dietary quality because it necessitates increased fruit and vegetable consumption. Lastly, Rose et al's study lasted for one month, whereas this intervention lasted one week. ${ }^{24}$

Several focus themes emerged about a sustainable food system that indicated that participants changed their attitudes and behaviors. Barriers to change acknowledged by study participants were similar to those identified in literature about food choice, namely, convenience and finances. ${ }^{25}$ As an example of the usefulness of focus group and journal entry information, several students identified being restricted to campus dining halls as a barrier for change. The dietary recall analysis indicated that in reality there were no significant differences in percentages of local and organic foods. Participants also indicated different levels of knowledge about sustainable food systems and HI's model at pretest due to coursework, peers, or life experiences, but this level of knowledge did not translate into significant differences in dietary practices from pretest to posttest to follow-up. Perhaps this can be explained by the "attitude-behavior intention" disconnect described by Vermeir and Verbeke, ${ }^{26}$ who explained that even with a positive attitude toward sustainable food systems, purchasing behaviors are not always consistent with an individual's belief system.

Significant increases in the percentage of local foods consumed were reported from individuals who completed follow-up dietary recalls $(n=$ 22), but no significant differences were found in individuals who completed pretest to posttest surveys only. Survey data indicated that participants who completed follow-up data placed increased importance on local foods, waste management, and overconsumption and decreased importance on the price of food as the study progressed. Perhaps these interests account for the changes in percentage of organic food consumption, especially as the perception of high prices for organic and local foods proliferates. ${ }^{27}$

The results show that behavioral and attitude changes were made in regards to sustainable food system participation, but changes in local and organic food consumption were contingent on a low level of intake before the AB. These results can be corroborated by the participant's desire for a deeper level of immersion on the trips. To find significant dietary changes, HI 
should consider more graduated programming for participants. In addition, participants identified long-term changes (ie, switching career paths) that could be measured through longitudinal studies to document the greater impacts that $\mathrm{AB}$ has beyond dietary changes.

\section{LIMITATIONS}

This study included no control group. Researchers used several dynamic qualitative and quantitative measures to account for potential validity biases. Plausible limitations also arise from the sample size. Participants likely to enroll in the $\mathrm{AB}$ had demographics similar to those of individuals who participate in sustainable food systems in the general population (ie, female, white, and highly educated), thus inhibiting the generalizability of the study. Participants arrived at the $\mathrm{AB}$ with various levels of knowledge and behaviors regarding sustainable food systems and the HI model. This inhibited deeper level learning about sustainable food systems and HI when desired, possibly changing the intervention effect.

\section{CONCLUSIONS}

As the first report about the dietary impacts of $\mathrm{AB}$ programs, potential changes in attitudes and behaviors regarding sustainable food systems were found for students. In addition, a framework was established for measuring dietary changes in like programs. Moreover, researching the impacts of $\mathrm{AB}$ programs can be useful for both academics and practitioners in linking research to practice and vice versa. Academics who are researchers and teachers can use their teaching role to also fulfill their research goals. Practitioners can measure and better understand the ability of their programs to achieve missions and objectives of their organization and to change participant behavior. Both can answer the question: What are experiential learning activities instructing our students and yielding in our communities? Further studies should test the impacts of sustainable food system $\mathrm{AB}$ programs with more diverse college groups, possibly as a longitudinal study. In fact, HI's College and University Advisory Council is currently investigating approaches to facilitate $\mathrm{AB}$ experiences for a broader scope of college-age students and methods to further measure the impacts of these programs.

\section{REFERENCES}

1. Sustainable Endowments Institute. The college sustainability report card. Available at: http://www.greenreportcard.org/. Accessed February 5, 2011. 
2. Real Food Challenge. Real food challenge. Available at: http://realfoodchallenge. org/. Accessed May 28, 2011.

3. Sustainable Agriculture Education Association. Academic programs. Available at: http://www.sustainableaged.org/Resources/AcademicPrograms/tabid/86/Default. aspx. Accessed June 28, 2011.

4. Lyson T. Civic Agriculture: Reconnecting Farm, Food, and Community. Lebanon, NH: Tufts University; 2004.

5. Clugston R, Calder W. Food and higher education for sustainable development. J Educ Sustain Dev. 2007;1:209-218.

6. Wright D. Civic engagement through civic agriculture: using food to link classroom and community. Teach Sociol. 2006;34:224-235.

7. Wilkins J, Bowdish E, Sobal J. University student perceptions of seasonal and local foods. J Nutr Educ. 2000;32:261-268.

8. Poddar K, Hosig K, Nickols-Richardson S, Anderson E, Herbert W, Duncan S. Low-fat dairy intake and body weight and composition changes in college students. J Am Diet Assoc. 2009;109:1433-1438.

9. Racette S, Deusinger S, Strube M, Highstein G, Deusinger R. Changes in weight and health behaviors from freshman through senior year of college. J Nutr Educ Behav. 2008;40:39-42.

10. Rose N, Hosig K, Davy B, Serrano E, Davis L. Whole-grain intake is associated with body mass index in college students. J Nutr Educ Behav. 2007;39:90-94.

11. Wengreen H, Moncurm C. Change in diet, physical activity, and body weight among young-adults during the transition from high school to college. Nutr J. 2009;8:32.

12. Aaker J. The Heifer Model: Cornerstones Values-Based Development. Little Rock, Ark: Heifer International; 1996.

13. Heifer International. Volunteer at Heifer Learning Center at Heifer Ranch. Available at: http://www.heifer.org/. Accessed February 5, 2010.

14. Stokols D. Translating social ecological theory into guidelines for community health promotion. Am J Health Promot. 1996;10:282-298.

15. Israel B, Eng E, Schulz A, Parker E. Methods in Community-Based Participatory Research for Health. San Francisco, Calif: Jossey-Bass; 2005.

16. Sallis J, Owen N. Ecological models of health behavior. In: Glanz K, Rimer B, and Lewis FM, eds. Health Behavior and Health Education: Theory, Research, and Practice. 4th ed. San Francisco, Calif: Jossey-Bass; 2007.

17. Carter R, Sharbaugh C, Stapell C. Reliability and validity of the 24-hour recall. $J$ Am Diet Assoc. 1981;79:542-547.

18. Posner B, Martin-Munley S, Smigelski C, et al. Comparison of techniques for estimating nutrient intake: the Framingham Study. Epidemiology. 1992;3:171-177.

19. Thomson C, Giuliano A, Rock C, et al. Measuring dietary change in a diet intervention trial: comparing food frequency questionnaire and dietary recalls. $A m J$ Epidemiol. 2003;157:754-762.

20. Krueger R, Casey M. Focus Groups: A Practical Guide for Applied Research. 4th ed. Thousand Oaks, Calif: Sage; 2009.

21. SPSS Inc. SPSS for Macintosh: Version Rel. 17.0.0. Chicago, IL: SPSS Inc; 2008.

22. Axxya Systems. Nutritionist Pro ${ }^{\circledR}$ : Version 3.1. Stafford, TX: Axxya Systems; 2009.

23. Strauss A, Corbin J. Basics of Qualitative Research: Grounded Theory Procedures and Techniques. Newbury Park, Calif: Sage; 1990. 
24. Rose N, Serrano E, Hosig K, Haas C, Reaves D, Nickols-Richardson S. The 100mile diet: a community approach to promote sustainable food systems impacts dietary quality. J Hunger Environ Nutr. 2008;3:270-285.

25. Glanz K, Basil M, Maibach E, Goldber J, Snyder D. Why Americans eat what they do: taste, nutrition, cost, convenience, and weight control concerns as influences on food consumption. J Am Diet Assoc. 1998;98:1118-1126.

26. Vermeir I, Verbeke W. Sustainable food consumption: exploring the consumer "attitude-behavioral intention" gap. J Agric Environ Ethics. 2006;19:169-194.

27. Pirog R, McCann N. Is local food more expensive? Available at: http://www. leopold.iastate.edu/pubs/staff/prices.html. Accessed February 12, 2011. 